\title{
Prevention and treatment of cytomegalovirus infection in transplant recipients
}

\author{
JUTTA K PREIKSAITIS, MD, FRCPC
}

\begin{abstract}
JK PREIKSAITIS. Prevention and treatment of cytomegalovirus infection in transplant recipients. Can J Infect Dis 1993;4(Suppl C):43C-50C. Over the past decade, significant progress has been made in the understanding of the molecular biology of cytomegalovirus (CMV) and the pathogenesis of CMV infection and disease. The introduction of antiviral agents with efficacy against CMV, coupled with rapid diagnostic techniques in the laboratory, have resulted in the design of a number of regimens to prevent, modify and treat CMV infections in transplant recipients. Strategies for preventing CMV infection, including donorrecipient matching, the use of CMV 'safe' cellular blood products, passive and active immunization, and prophylactic antiviral drugs are discussed. Clinical trials of antiviral drugs alone, or in combination with immunoglobulin for the treatment of CMV disease are reviewed.
\end{abstract}

Key Words: Bone marrow transplantation, Cytomegalovirus, Organ transplantation

\section{Prévention et traitement de l'infection à cytomégalovirus chez les receveurs de transplantation}

RÉSUMÉ: Au cours de la décennie écoulée, de grands progrès ont été accomplis dans la compréhension de la biologie moléculaire du cytomégalovirus (CMV), de la pathogenèse de l'infection à CMV et de la maladie qui en résulte. L'introduction d'agents antiviraux efficaces contre le CMV, doublée de techniques diagnostiques rapides en laboratoire ont permis la conception de certains schémas aptes à prévenir. modifier et traiter les infections à CMV chez les receveurs de transplantation. Les stratégies prophylactiques contre l'infection à CMV, y compris la correspondance donneur-receveur, l'utilisation de produits sanguins cellulaires dépourvus de CMV, l'immunisation passive et active et les médicaments antiviraux prophylactiques sont présentés. Les essais cliniques portant sur des médicaments anti-viraux seuls ou en combinaison avec l'immunoglobuline pour le traitement de la maladie à CMV sont passés en revue également. 
$\mathrm{C}$ YTOMEGALOVIRUS (CMV) INFECTION IS THE MOST COMMON infectious complication seen after solid organ and bone marrow transplantation. Acute CMV infection has direct consequences to the transplant recipient, often leading to significant morbidity and even mortality. Common symptoms include: fever; bone marrow suppression leading to leukopenia and thrombocytopenia; gastrointestinal disease including ulceration, perforation and hemorrhage; hepatitis; and pneumonitis (1). Encephalitis is seen less commonly and chorioretinitis is a relatively infrequent and late complication of CMV infection in this setting. As well as direct effects, CMV has indirect effects on the host (1). The virus is immunosuppressive and predisposes the host to superinfection with bacterial, fungal and parasitic pathogens. Whether CMV infection precipitates acute graft rejection remains controversial. CMV also has been implicated as a contributing factor to the sequelae leading to late graft failure, which include graft atherosclerosis in the heart transplant recipient, vanishing bile duct syndrome in the liver transplant recipient and bronchiolitis obliterans in the lung transplant recipient.

There are several potential sources of CMV infection in the transplant recipient (1). Patients seropositive prior to transplantation may undergo reactivation of endogenous virus. The transfusion of cellular blood products provides an additional potential source of infection. The most important source of CMV infection in solid organ and bone marrow transplantation is the seropositive donor organ or bone marrow. Recent evidence in renal and heart allograft recipients suggests that in CMV seropositive transplant recipients, reinfection by CMV strains transmitted by the donor organ frequently occurs (2).

Several factors have been found to influence the severity of CMV disease in allograft recipients (1). The type of allograft received appears to be important. For example, renal allograft recipients appear to experience less CMV-associated morbidity than heart, lung and liver transplant recipients. This may be an indirect reflection of the aggressiveness of immunosuppression required to prevent graft rejection. However, there appears to be a predilection for CMV to appear first in the transplanted organ and result in major morbidity at this site. For example, liver transplant recipients are predisposed to CMV hepatitis, and lung transplant recipients to CMV pneumonitis. Bone marrow transplant recipients appear to be at significantly higher risk of CMV-associated interstitial pneumonitis, and the risk of its occurrence and the severity of disease have been linked to the presence and severity of graft versus host disease in this subgroup of patients (3). In general, patients who are CMV seronegative prior to transplant and experience a primary CMV infection, are at greater risk of CMV disease than those seropositive prior to transplant who experience CMV reactivation or reinfection (1). Although this remains somewhat controversial,
TABLE 1

Strategies for the prevention of cytomegalovirus disease

1. Matching of donor-recipient serostatus

2. Screening of cellular blood products

3. Vaccine

4. Passive immunotherapy

5. Prophylactic drugs:

Interferon-alpha

Acyclovir

Foscarnet

Ganciclovir

Valine ester of acyclovir

6. Combination of passive immunotherapy plus antiviral drug

7. Pre-emptive therapy

the bulk of evidence suggests that in these seropositive patients, reinfection events are associated with more morbidity than endogenous reactivation of virus $(1,2)$. The use of polyclonal or monoclonal (OKT3) antilymphocyte globulins have also been demonstrated to increase the risk of CMV disease in solid organ transplant recipients $(1,4)$.

Over the past decade, significant progress has been made in our understanding of the molecular biology of CMV and the pathogenesis of CMV infection and disease. The introduction of antiviral agents with efficacy against CMV, coupled with rapid diagnostic techniques in the laboratory, have resulted in the design of a number of regimens to prevent, modify and treat CMV infections in transplant recipients. Many of the reports of the use of these regimens represent uncontrolled studies. The use of historical controls is particulary difficult in the transplant setting with its rapidly changing immunosuppressive protocols. Therefore this paper deals largely with interventions that have been studied using controlled trials.

\section{PREVENTION OF CMV INFECTIONS}

Some of the approaches that have been used for the prevention of CMV disease are listed in Table 1.

CMV infection is extremely common after transplantation and in most patients is asymptomatic. In choosing a strategy for the prevention of CMV disease, it is important to identify clearly, through epidemiological or laboratory parameters, the patients who are at highest risk of CMV-associated morbidity and to target this subgroup specifically for preventive strategies. The potential toxicity of the regimen proposed as well as the cost should be considered. One must also examine the logistics of the delivery of the preventive regimen. Since often the greatest portion of the risk period for CMV infection after transplantation is spent in an out-patient setting, oral agents would clearly be preferable to intravenously administered products.

Donor recipients - CMV matching: Because the source of CMV infection in most cases of primary CMV 
TABLE 2

Transfusion-acquired cytomegalovirus infection in seronegative bone marrow transplant recipients

\begin{tabular}{|c|c|c|c|c|c|}
\hline $\begin{array}{l}\text { Study } \\
\text { (reference) }\end{array}$ & Group & $\begin{array}{l}\text { Number of } \\
\text { patients }\end{array}$ & $\begin{array}{l}\text { Number } \\
\text { infected }\end{array}$ & Significance & Conclusions \\
\hline $\begin{array}{l}\text { Bowden et al } \\
\text { (allogeneic) } \\
\text { (7) }\end{array}$ & $\begin{array}{l}\text { Control } \\
\text { (standard blood) }\end{array}$ & 28 & 8 & $P<0.007$ & $\begin{array}{l}\text { CMV seronegative blood products } \\
\text { significantly reduced the risk of } \\
\text { CMV infection of seronegative } \\
\text { but not seropositive marrows }\end{array}$ \\
\hline \multirow{2}{*}{$\begin{array}{l}\text { Bowden et al } \\
\text { (autologous/some } \\
\text { allogeneic) } \\
\text { (8) }\end{array}$} & $\begin{array}{l}\text { Control } \\
\text { (standard blood) }\end{array}$ & 30 & 0 & \multirow[t]{2}{*}{$P<0.001$} & \multirow{2}{*}{$\begin{array}{l}\text { Leukocyte-depleted platelets and } \\
\text { CMV-seronegative red blood cells } \\
\text { are highly effective in preventing } \\
\text { primary CMV infection }\end{array}$} \\
\hline & $\begin{array}{l}\text { Study } \\
\text { (CMV-red blood } \\
\text { cells, leukocyte- } \\
\text { depleted platelets, } \\
\text { centrifugation) }\end{array}$ & 35 & 7 & & \\
\hline $\begin{array}{l}\text { Miller et al } \\
\text { (allogeneic) } \\
\text { (9) }\end{array}$ & $\begin{array}{l}\text { Control } \\
\text { (standard blood) }\end{array}$ & 44 & 14 & $P<0.006$ & $\begin{array}{l}\text { Confirms study of Bowden et al } \\
\text { above. However, the use of } \\
\text { seronegative blood products did } \\
\text { not improve survival }\end{array}$ \\
\hline
\end{tabular}

CMV Cytomegalovirus

infection in solid organ transplant recipients is the CMV seropositive organ, it has been suggested that the use of CMV seropositive donors be avoided in CMV seronegative recipients. However, the shortage of suitable donor organs and the presence of critical illness in the recipient often makes this approach impractical in all but the largest transplant programs.

Use of CMV 'safe' cellular blood products: CMV is known to be transmitted by blood transfusion. Despite the fact that in Canada approximately 50\% of blood products come from CMV seropositive donors, cellular blood products are a relatively infrequent source of CMV infection compared with the seropositive donor organ or bone marrow (5). CMV is believed to be transmitted in the latent form in the leukocyte fraction of cellular blood products and reactivated in the recipient. The use of CMV seronegative cellular blood products or processing techniques, such as the use of frozen de-glycerolized red blood cells, differential centrifugation of platelets and the use of the new generation leukocyte filters, will render these products CMV 'safe' (5). However, these procedures are associated with considerable cost. Although the use of CMV seronegative blood products for CMV seronegative recipients (R-) of CMV seronegative donor organs (D-) or bone marrow have been recommended by some authors (6), the efficacy of this approach has only been proven in bone marrow transplantation (7-9) (Table 2). In allogeneic and autologous bone marrow transplantation where the use of cellular blood products, particulary highly leukocyte-contaminated platelet units, is large, the use of CMV 'safe' blood significantly reduces the risk of CMV infection. Interestingly, Miller et al (9) found that this decreased risk of CMV infection was not associated with improved patient survival. It is not clear that these findings can be extrapolated to the solid organ transplant population.
Whether the use of CMV 'safe' blood products in R-Dkidney recipients would have any significant impact on CMV disease after renal transplantation is questionable (5). In the age of erythropoietin administration, kidney allograft recipients usually receive only small numbers of red cell units when transfused. In the more heavily transfused heart, lung and liver transplant recipient, the incidence of transfusion-acquired infection is also surprisingly low, although in the highly transfused liver transplant recipient, incidences as high as 20\% in the D-R- subgroup have been reported (personal communication) (5). There is a clear need for controlled studies to determine the impact of the use of CMV 'safe' blood products in solid organ transplantation prior to recommending this as routine policy for D-R- transplant recipients.

Vaccine: Plotkin et al (10) have recently reported the results of a 10-year study of the effect of a live attenuated CMV Towne vaccine on CMV disease after renal transplantation. This was a double-blind, placebo controlled trial. They demonstrated that the vaccine was well-tolerated and safe. Although the vaccine did not prevent CMV infection, vaccination of CMV seronegative renal transplant recipients resulted in a reduction in the severity of CMV disease in this subgroup of patients. There are theoretical risks associated with using a live DNA virus vaccine, particulary in patient groups who are not immunocompetent because of their chronic disease state prior to transplant. The future of this vaccine will be somewhat dependent on how it compares in efficacy, cost and ease of administration with prophylactic regimens involving the use of immunoglobulin and antiviral agents.

Passive immunotherapy: In the early 1980s, the availability of intravenous immune globulin preparations and the lack of an antiviral drug with significant activity 
TABLE 3

Controlled trials of immune globulin for cytomegalovirus prophylaxis

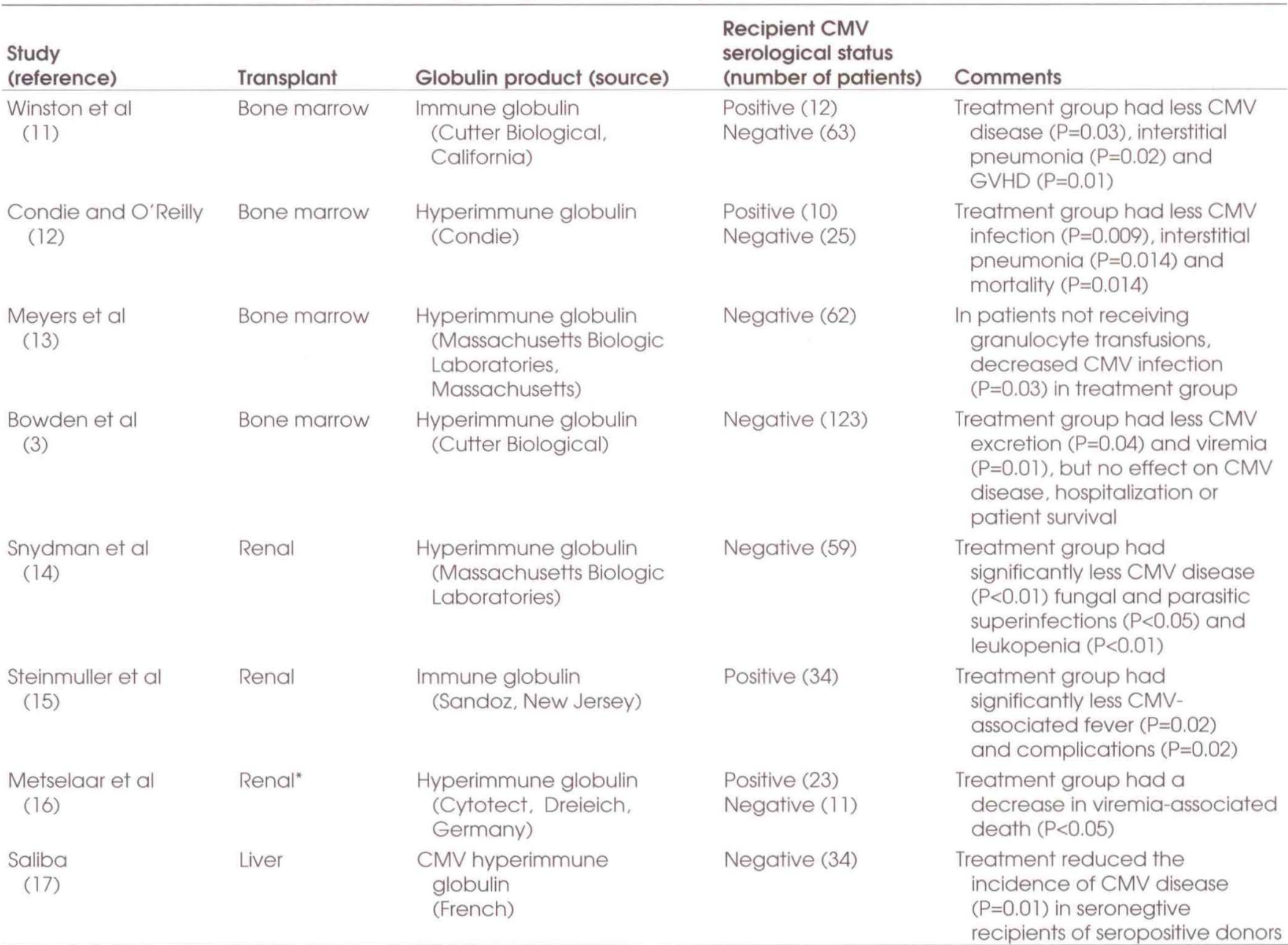

CMV Cytomegalovirus; GVHD Graft-versus-host disease; "Treatment initiated with antirejection therapy

against CMV, led to a number of clinical trials examining the role of passive antibody as prophylaxis for CMV disease after transplantation.

In transplant recipients, CMV disease occurs in the presence of high levels of neutralizing antibody (2). The effective anti-CMV component in immunoglobulin preparations is unknown. It is therefore impossible to standardize the product and accurately determine optimal dosing regimens. It is also not clear whether 'hyperimmune' CMV products defined using enzyme immunoassay or neutralizing titres are clearly superior to standard immunoglobulin. The majority of controlled studies using passive immunization have been carried out in the bone marrow transplant setting (Table 3). In these patients, the issue is further complicated by the observation that high dose intravenous immunoglobulin affects the incidence of graft versus host disease, presumably through its immunomodulating function. Since graft versus host disease is a known risk factor for severe CMV infection, specifically interstitial CMV pneumonitis, passive immunization in this setting may be playing an indirect role in modifying CMV disease. Many of these studies included both seronegative and seropositive recipients who received marrows from both seronegative and seropositive donors. This makes data analysis difficult. The largest study, by Bowden et al (3), examined 123 seronegative recipients of seropositive donor marrows and found no effect of hyperimmune intravenous immunoglobulin on CMV disease, although a decrease in CMV excretion and viremia were observed. This study, however, showed no clear effect of immunoglobulin on graft-versus-host disease. The number of studies of the immunoglobulin prophylaxis in solid organ transplantation, particularly in extrarenal transplant recipients, is also limited. In seronegative recipients of seropositive donor kidneys, Snydman et al (14), found that prophylactic hyperimmune CMV globulin had a significant effect on CMV disease, fungal and parasitic superinfections, and leukopenia. However, the protective effect of the immunoglobulin was found to be attenuated by increased immunosuppression, specifically by the use of antilymphocyte globulins 
TABLE 4

Controlled trials of antiviral drugs for cytomegalovirus prophylaxis

\begin{tabular}{|c|c|c|c|c|}
\hline Study (reference) & Transplant & Drug & Dosage & Comments \\
\hline $\begin{array}{l}\text { Hirsch et al } \\
\text { (19) }\end{array}$ & $\begin{array}{l}\text { Renal } \\
\text { (seropostitive) }\end{array}$ & Interferon-alpha & $\begin{array}{l}3 \times 10^{6} \text { units preoperatively: } \\
3 \text { per week for } 6 \text { weeks, then } \\
2 \text { per week for } 8 \text { weeks }\end{array}$ & $\begin{array}{l}\text { Treatment group had less CMV } \\
\text { disease ( } P=0.03) \text {; opportunistic } \\
\text { superinfections occurred only in } \\
\text { patients given placebo }\end{array}$ \\
\hline $\begin{array}{l}\text { Meyers et al } \\
\text { (20) }\end{array}$ & $\begin{array}{l}\text { Allogeneic bone } \\
\text { marrow } \\
\text { (seropositive for } \\
\text { both HSV and } \\
\text { CMV) }\end{array}$ & $\begin{array}{l}\text { Acyclovir } \\
\text { (intravenous) }\end{array}$ & $\begin{array}{l}500 \mathrm{mg} / \mathrm{m}^{2} \text { every } 8 \mathrm{~h} \text { from } \\
\text { preoperative day } 5 \text { to } \\
\text { postoperative day } 30\end{array}$ & $\begin{array}{l}\text { Treatment group had less CMV } \\
\text { infection ( } P=0.0001) \text {, CMV disease } \\
(P=0.008) \text { and improved survival } \\
(P=0.002)\end{array}$ \\
\hline $\begin{array}{l}\text { Balfour et al } \\
\text { (21) }\end{array}$ & Renal & Acyclovir (oral) & $800 \mathrm{mg}$ qid for 12 weeks & $\begin{array}{l}\text { Treatment group had less CMV } \\
\text { infection }(P=0.01) \text { and CMV } \\
\text { disease }(P=0.002) \text {; greatest } \\
\text { prophylactic benefit observed in } \\
\text { seronegative recipients who } \\
\text { received a kidney from a } \\
\text { seropositive donor }\end{array}$ \\
\hline
\end{tabular}

CMV Cytomegalovirus; HSV Herpes simplex virus

for antirejection therapy (18). Since this is the patient group at greatest risk of serious CMV disease, the use of immunoglobulin alone for CMV prophylaxis probably represents a suboptimal strategy. The use of intravenous globulin preparations also has disadvantages in the form of high cost and the need for repetitive, lengthly intravenous infusions. The introduction of drugs active against CMV may replace the need for a passive immunization or result in its use in combination protocols.

Antiviral drugs (Table 4): Before the introduction of antiviral drugs specific for CMV infection, interferonalpha was studied as a prophylactic agent for CMV infection in renal transplant recipients. In a group of seropositive renal transplant recipients, interferonalpha was found to decrease the incidence of CMV disease and opportunistic superinfections (19). However, several episodes of acute vascular rejection associated with the use of interferon-alpha were later documented (1). Combined with the high cost of this product, this has largely eliminated it as a potential prophylactic agent in the transplant setting.

Acyclovir inhibits CMV replication in vitro although it does so at much higher concentrations than are required to suppress replication of herpes simplex virus or varicella zoster virus. Although it has not been shown to be effective in the treatment of established CMV disease, it appears to have some effect as a prophylactic agent. In a study using intravenous acyclovir administered to bone marrow transplant recipients for the first 30 days, Meyers et al (20) observed a significant decrease in CMV infection and disease. Balfour et al (21) found a similar decrease in CMV disease when renal allograft recipients received high dose oral acyclovir prophylactically. In this study, this effect was only statistically significant in the seronegative recipient of a seropositive donor kidney. Surprisingly, this effect was observed in the presence of plasma levels lower than those required to inhibit CMV replication in vitro (22). New acyclovir derivatives which result in significantly higher drug levels in plasma when given orally are under study for CMV prophylaxis.

Ganciclovir (23) and foscarnet (24) are two antiviral agents which demonstrate significantly better inhibition of CMV replication in vitro than acyclovir. However, the bone marrow suppressive effect of ganciclovir and the nephrotoxicity of foscarnet has led to a reluctance to use these drugs routinely as prophylactic agents, particularly in bone marrow transplant recipients and in patients receiving cyclosporine, respectively. Ganciclovir prophylaxis has been studied in heart transplant recipients (25). A one-month course of prophylactic ganciclovir resulted in a reduced incidence of CMV disease in seropositive patients. In this study no effect was observed in seronegative recipients of seropositive donor hearts. A significant beneficial effect of ganciclovir prophylaxis on the incidence of CMV disease and pneumonitis in bone marrow transplant recipients was reported by Atkinson et al (26). However, this study used historical controls. In lung transplant recipients, two studies examining the use of prophylactic ganciclovir followed by oral acyclovir have reported contradictory findings with respect to efficacy $(27,28)$. Foscarnet prophylaxis has been studied in a phase I and phase II trial in the bone marrow transplant setting (29). This initial study looks promising with respect to the efficacy of foscarnet on CMV disease. However, significant renal toxicity was observed when foscarnet was used in combination with amphotericin B. Both ganciclovir and foscarnet have a major disadvantage in 
TABLE 5

The use of the 'pre-emptive strike' for the prophylaxis or early treatment of cytomegalovirus disease

\begin{tabular}{|c|c|c|c|}
\hline Study (reference) & Patients & Design & Comments \\
\hline $\begin{array}{l}\text { Schmidt et al } \\
\text { (31) }\end{array}$ & $\begin{array}{l}\text { Bone marrow } \\
\text { transplant } \\
\text { recipients }\end{array}$ & $\begin{array}{l}\text { Treatment with ganciclovir }(5 \mathrm{mg} / \mathrm{kg} 12 \mathrm{~h} \text { for } \\
\text { two weeks, then } 5 \mathrm{mg} / \mathrm{kg} / \text { day } 5 \text { times a } \\
\text { week to day } 120 \text { ) based on BAL culture } \\
\text { positivity on day } 35 \text { (controlled randomized) }\end{array}$ & $\begin{array}{l}\text { Decreased incidence of CMV pneumonitis } \\
(P=0.01)\end{array}$ \\
\hline $\begin{array}{l}\text { Goddrich et al } \\
\text { (32) }\end{array}$ & $\begin{array}{l}\text { Bone marrow } \\
\text { transplant } \\
\text { recipients }\end{array}$ & $\begin{array}{l}\text { Treatment with ganciclovir ( } 5 \mathrm{mg} / \mathrm{kg} \text { every } \\
12 \mathrm{~h} \text { for } 1 \text { week, then } 5 \mathrm{mg} / \mathrm{kg} / \mathrm{day} \text { to day } \\
100 \text { ) based on positive surveillance cultures } \\
\text { of throat swabs, urine, blood, BAL } \\
\text { (controlled randomized) }\end{array}$ & $\begin{array}{l}\text { Decreased incidence of CMV disease } \\
\quad(P<0.00001) \text { and improved survival }(P=0.041)\end{array}$ \\
\hline $\begin{array}{l}\text { Hibberd et al } \\
\text { (4) }\end{array}$ & $\begin{array}{l}\text { Renal } \\
\text { transplant } \\
\text { recipients }\end{array}$ & $\begin{array}{l}\text { Treatment with ganciclovir ( } 2 \mathrm{mg} / \mathrm{kg} / \mathrm{day} \text { ) in } \\
\text { conjunction with OKT3 rejection therapy } \\
\text { (pilot study) }\end{array}$ & $\begin{array}{l}\text { Decreased incidence of symptomatic CMV } \\
\text { disease compared with historical controls }\end{array}$ \\
\hline
\end{tabular}

BAL Bronchoalveolar lavage; CMV Cytomegalovirus

\begin{tabular}{|c|c|}
\hline Study (reference) & Survival of first episode (\%) \\
\hline Emanuel et al (33) & 8 of $10(80)$ \\
\hline Reed et al (34) & 13 of $25(52)$ \\
\hline Schmidt et al (35) & 9 of $13(69)$ \\
\hline Ljungman et al (36) & 15 of $49(31)$ \\
\hline
\end{tabular}

their requirement for intravenous administration. There is a clear need for better anti-CMV drugs that can be administered orally for use in prophylactic regimens to prevent CMV disease.

'Pre-emptive strike': The observed toxicity of ganciclovir (23) and foscarnet (24) coupled with the observation that only a subset of transplant recipients are at significant risk for CMV disease, has lead to a strategy of intervention which lies somewhere in the spectrum between late prophylaxis and early treatment. This approach has been called the 'pre-emptive strike'. It is based on the use of antiviral therapy initiated in response to evidence of CMV infection such as positive CMV cultures during laboratory surveillance of patients or clinical parameters such as the use of antilymphocyte globulins for rejection therapy (30). This approach has been demonstrated to be extremely effective in bone marrow transplant recipients (Table 5) $(31,32)$. Studies in solid organ transplantation are extremely limited. However, in a pilot study of renal transplant recipients, the use of ganciclovir in combination with OKT3 rejection therapy had a significant impact on CMV disease compared with historical controls (4). In this study, the dose of ganciclovir used was significantly lower than the usual therapeutic dose used to treat established disease. The presence of viremia has been identified as a risk factor for the development of a symptomatic CMV infection $(30,32)$. The development of rapid diagnostic tests to detect and quantify viremia such as the direct antigenemia assay and polymerase chain reaction may allow simple and efficient monitoring of patients after transplant. This may allow identification of patients at high risk of CMV disease leading to a more selective use of the 'pre-emptive strike' approach.

\section{TREATMENT OF CMV DISEASE}

Over the past two decades, the acquired immunodeficiency syndrome (AIDS) epidemic and an increasing number of solid organ transplant recipients resulted in large numbers of immunocompromised patients with serious CMV disease. This led to the extensive use of ganciclovir and foscarnet on a compassionate plea basis, and the strong impression by many clinicians that treatment of CMV disease with these drugs resulted in significant benefit. Unfortunately, placebo controlled, double-blind protocols were never used to validate the anti-CMV efficacy of these agents in vivo. Ethical considerations will now likely prohibit these trials from being done. Much of the data regarding the efficacy of foscarnet and ganciclovir is therefore based on outcomes in treated patients compared with historical controls $(23,24)$.

The most common forms of CMV disease include fever, pneumonitis, gastrointestinal disease and retinitis. The best evidence for the efficacy of antiviral therapy for the treatment of CMV disease is found in the bone marrow transplant setting. CMV pneumonitis is a serious complication of bone marrow transplantation resulting in an $85 \%$ mortality. The use of ganciclovir or immunoglobulin alone does not affect a patient's survival. However, the combination of ganciclovir and immunoglobulin therapy has been found to result in a significant improvement in survival (Table 6) (33-36). Ganciclovir alone is effective in limiting viral replication. The mechanism by which immunoglobulin has an additive beneficial effect is not known. There is an increasing body of evidence to suggest that CMV pneumonitis is an immunopathological disease and that immunoglobulin may be acting as an immunomodulator or through its effect on graft-versus-host disease. 
Although both an antiviral drug and immunoglobulin appear to be required in the setting of CMV pneumonitis in bone marrow transplant and perhaps lung transplant recipients, it is not clear whether the immunoglobulin therapy is necessary for the treatment of pneumonitis in other solid organ transplant recipients.

Although there are large numbers of uncontrolled reports suggesting that ganciclovir may be of clinical benefit in the treatment of CMV gastrointestinal disease (23), controlled studies are limited. In a placebo controlled, randomized study of ganciclovir for the treatment of CMV gastroenteritis in bone marrow transplant recipients, it was found that although virus shedding was effectively terminated by antiviral therapy, there was no difference in either clinical symptoms or endoscopic appearance between the groups after treatment (37). Although there are no data in solid organ transplant recipients, the results of a recent placebo controlled trial of ganciclovir for CMV colitis in AIDS patients have been reported (38). The investigators found that ganciclovir treatment was associated with improved endoscopy scores, less extracolonic CMV disease and less weight loss. The efficacy of either foscarnet or ganciclovir for treatment of CMV gastrointestinal disease in solid organ transplant recipients remains unproven. There is no evidence to suggest that the use of adjunctive immunoglobulin therapy is beneficial.

Unlike AIDS patients, organ transplant recipients rarely develop CMV chorioretinitis. Although foscarnet

\section{REFERENCES}

1. Rubin RH. Impact of cytomegalovirus infection on organ transplant recipients. Rev Infect Dis 1990;12(Suppl 7):S754-66.

2. Chou S. Neutralizing antibody responses to reinfecting strains of cytomegalovirus in transplant recipients. $J$ Infect Dis 1989;160:16-21.

3. Bowden RA, Fisher LD, Rogers K, Cays M, Meyers JD. Cytomegalovirus (CMV)-specific intravenous immunoglobulin for the prevention of primary CMV infection and disease after marrow transplant. J Infect Dis 1991; 164:483-7.

4. Hibberd PL, Tolkoff-Rubin NE, Cosimi AB, et al. Symptomatic cytomegalovirus disease in the cytomegalovirus antibody seropostitive renal transplant recipient treated with OKT3. Transplantation 1992;53:68-72.

5. Preiksaitis JK. Indications for the use of cytomegalovirus-seronegative blood products. Transfusion Med Rev 1991;5:1-17.

6. Hillyer CD, Snydman DR, Berkman EM. The risk of cytomegalovirus infection in solid organ and bone marrow transplant recipients: Transfusion of blood products. Transfusion 1990;30:659-66.

7. Bowden RA, Sayers M, Flournoy N, et al. Cytomegalovirus immune globulin and seronegative blood products to prevent primary cytomegalovirus infection after marrow transplantation. N Engl J Med 1986;314:1006-10.

8. Bowden RA, Slichter SJ, Sayers MH, Mori M, Cays MJ, Meyers JD. Use of leukocyte-depleted platelets and cytomegalovirus-seronegative red blood cells for prevention of primary cytomegalovirus infection after marrow transplant. Blood 1991;78:246-50. may have some advantages over ganciclovir in the treatment of CMV retinitis in AIDS, this may be due to the effect of foscarnet on human immunodeficiency virus infection rather than its direct effect on CMV replication. In the transplant setting, there is no evidence that foscarnet has any clear advantage over ganciclovir.

In the past when fever alone was the only symptom of CMV disease, treatment was usually not instituted. However, fever often results in significant patient morbidity, rehospitalization and extensive investigation. As experience with the use of ganciclovir and foscarnet increases, there has been a general trend among transplant physicians to institute antiviral therapy earlier in patients with symptomatic CMV infection with a view to preventing tissue invasive disease. Data to support the efficacy of this approach are lacking.

Although significant progress has been made, based on the evidence available, it is difficult to make definitive recommendations regarding the optimal regimens for either the prophylaxis or treatment of CMV disease. Much work remains to be done. There is a clear need for a better oral anti-CMV drug. The clinical usefulness of rapid diagnostic tests such as the quantitative direct antigenemia assay and polymerase chain reaction for the identification of patients at high risk of CMV disease should be examined. There is a need for further controlled studies comparing currently available regimens for both the prophylaxis and treatment of CMV disease.

9. Miller JW, McCullough J, Balfour HH. Prevention of cytomegalovirus infection following bone marrow transplantation: A randomized trial of blood product screening. Bone Marrow Transplant 1991;7:227-34.

10. Plotkin SA, Starr SSE, Friedman HM, et al. Effect of towne live virus vaccine on cytomegalovirus disease after renal transplant. A controlled trial. Ann Intern Med 1991;114:525-31.

11. Winston DJ, Ho WG, Lin C-H, et al. Intravenous immune globulin for prevention of cytomegalovirus infection and interstitial pneumonia after bone marrow transplantation. Ann Intern Med 1987;106:12-8.

12. Condie RM, O'Reilly RJ. Prevention of cytomegalovirus infection by prophylaxis with an intravenous. hyperimmune, native, unmodified cytomegalovirus globulin. Randomized trial in bone marrow transplant recipients. Am J Med 1984;76(Suppl 3A):134-41.

13. Meyers JD, Leszczynski J, Zaia JA, et al. Prevention of cytomegalovirus infection by cytomegalovirus immune globulin after marrow transplantation. Ann Intern Med 1983;98:442-6.

14. Snydman DR, Werner BG, Heinze-Lacey B, et al. Use of cytomegalovirus immune globulin to prevent cytomegalovirus disease in renal transplant recipients. N Engl J Med 1987;317:1049-54.

15. Steinmuller DR, Novick AC, Streem SB, Graneto D, Swift C. Intravenous immunoglobulin infusions for the prophylaxis of secondary cytomegalovirus infection. Transplantation 1990;49:68-70.

16. Metselaar HJ, Rothbarth PH, Brouwer RML, Wenting GJ, Jeekel J, Weimar W. Prevention of cytomegalovirusrelated death by passive immunization. Transplantation 
1989;48:264-6.

17. Saliba F, Arulnaden JL, Sugenheim J, et al. CMV hyperimmune globulin prophylaxis after liver transplantation: A prospective randomized controlled study. Transplant Proc 1989:21:2260-2.

18. Syndman DR. Cytomegalovirus immunoglobulins in the prevention and treatment of cytomegalovirus disease. Rev Infect Dis 1990;12(Suppl 7):S839-48.

19. Hirsch MS, Schooley RT, Cosimi AB, et al. Effects of interferon-alpha on cytomegalovirus reactivation syndromes in renal transplant recipients. N Engl J Med 1983;308: 1489-93.

20. Meyers JD, Reed EC, Shepp DH, et al. Acyclovir for prevention of cytomegalovirus infection and disease after allogeneic marrow transplantation. N Engl J Med 1988;318:70-5.

21. Balfour HH, Chace BA, Stapleton JT, Simmons RL, Fryd DS. A randomized, placebo-controlled trial of oral acyclovir for the prevention of cytomegalovirus disease in recipients of renal allografts. N Engl J Med 1989;320: 1381-7.

22. Fletcher CV, Englund JA, Edelman CK, Gross CR, Dunn DL, Balfour HH Jr. Pharmacologic basis for high-dose oral acyclovir prophylaxis of cytomegalovirus disease in renal allograft recipients. Antimicrob Agents Chemother 1991;35:938-43.

23. Faulds D, Heel RC. Ganciclovir: A review of its antiviral activity, pharmacokinetic properties and therapeutic efficacy in cytomegalovirus infections. Drugs 1990;39:597-638.

24. Chrisp P, Clissold SP. Foscarnet: A review of its antiviral activity, pharmacokinetic properties and therapeutic use in immunocompromised patients with cytomegalovirus retinitis. Drugs 1991;42:104-29.

25. Merigan TC, Renlund DG, Keay S, et al. A controlled trial of ganciclovir to prevent cytomegalovirus disease after heart transplantation. N Engl J Med 1992;326:1182-6.

26. Atkinson K, Downs K, Golenia M, et al. Prophylactic use of ganciclovir in allogeneic bone marrow transplantation: Absence of clinical cytomegalovirus infection. $\mathrm{Br} \mathrm{J}$ Haematol 1991;79:57-62.

27. Bailey TC, Trulock EP, Ettinger NA, Storch GA, Cooper JD. Powderly WG. Failure of prophylactic ganciclovir to prevent cytomegalovirus disease in recipients of lung transplants. J Infect Dis 1992;165:548-52.

28. Duncan SR, Paradis IL, Dauber JH, Yousem SA, Hardesty RL, Griffith BP. Ganciclovir prophylaxis for cytomegalovirus infections in pulmonary allograft recipients. Am Rev Respir Dis 1992;146:1213-5.

29. Reusser P, Gambertoglio JG, Lilleby KE, Mayers JD. Phase I-II trial of foscarnet for prevention of cytomegalovirus infection in autologous and allogeneic marrow transplant recipients. J Infect Dis 1992; 166:473-9.

30. The TH, van der Ploeg M, van den Berg AP, Vlieger AM, van der Giessen M, van Son WJ. Direct detection of cytomegalovirus in peripheral blood leukocytes - A review of the antigenemia assay and polymerase chain reaction. Transplantation 1992;54:193-8.

31. Schmidt GM, Horak DA, Niland JC, et al. A randomized, controlled trial of prophylactic ganciclovir for cytomegalovirus pulmonary infection in recipients of allogeneic bone marrow transplants. N Engl J Med 1991:324:1005-11.

32. Goodrich JM, Mori M, Gleaves CA, et al. Early treatment with ganciclovir to prevent cytomegalovirus disease after allogeneic bone marrow transplantation. N Engl J Med 1991:325:1601-7.

33. Emanuel D, Cunningham I, Jules-Elysee K, et al. Cytomegalovirus pneumonia after bone marrow transplantation successfully treated with the combination of ganciclovir and high-dose intravenous immune globulin. Ann Intern Med 1988;109:777-82.

34. Reed EC, Bowden RA, Dandliker PS, Lilleby KE, Meyers JD. Treatment of cytomegalovirus pneumonia with ganciclovir and intravenous cytomegalovirus immunoglobulin in patients with bone marrow transplants. Ann Intern Med 1988;109:783-8.

35. Schmidt GM, Kovacs A. Zaia JA, et al. Ganciclovir/ immunoglobulin combination therapy for the treatment of human cytomegalovirus-associated interstitial pneumonia in bone marrow allograft recipients. Transplantation 1988;46:905-7.

36. Ljungman $\mathrm{P}$, Engelhard D, Link $\mathrm{H}$, et al. Treatment of interstitial pneumonitis due to cytomegalovirus with ganciclovir and intravenous immune globulin: Experience of European bone marrow transplant group. Clin Infect Dis 1992;14:831-5.

37. Reed EC, Wolford JL, Kopecky KJ, et al. Ganciclovir for the treatment of cytomegalovirus gastroenteritis in bone marrow transplant patients. A randomized, placebocontrolled trial. Ann Intern Med 1990;112:505-10.

38. Dieterich DT, Kotler DP, Busch DF, et al. Ganciclovir treatment of cytomegalovirus colitis in AIDS: A randomized, double-blind, placebo-controlled multicenter study. $\mathrm{J}$ Infect Dis 1993;167:278-82. 


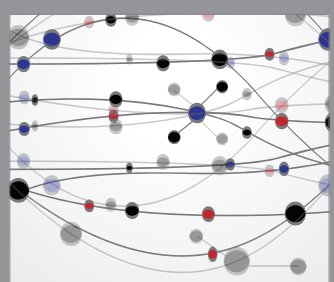

The Scientific World Journal
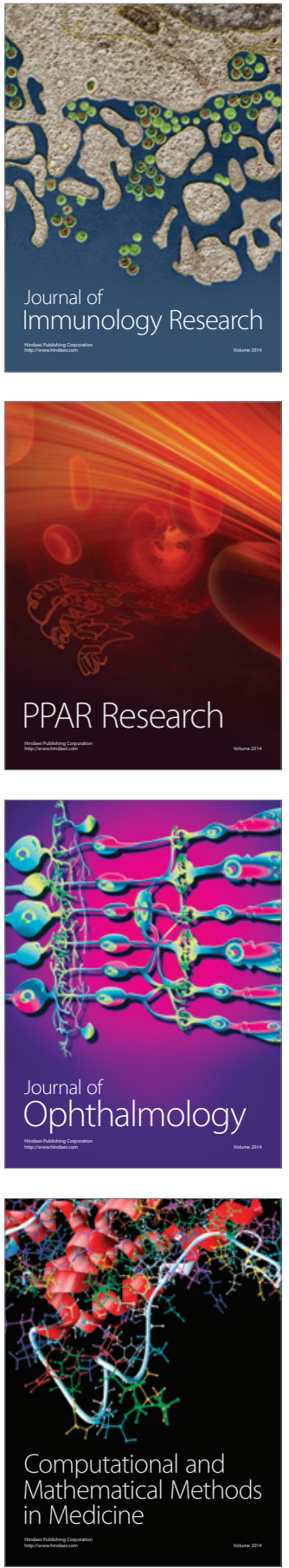

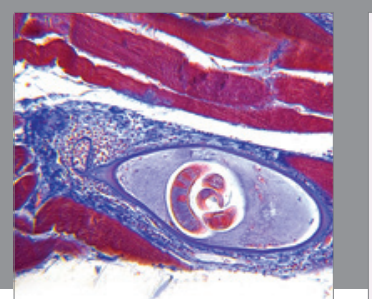

Gastroenterology Research and Practice

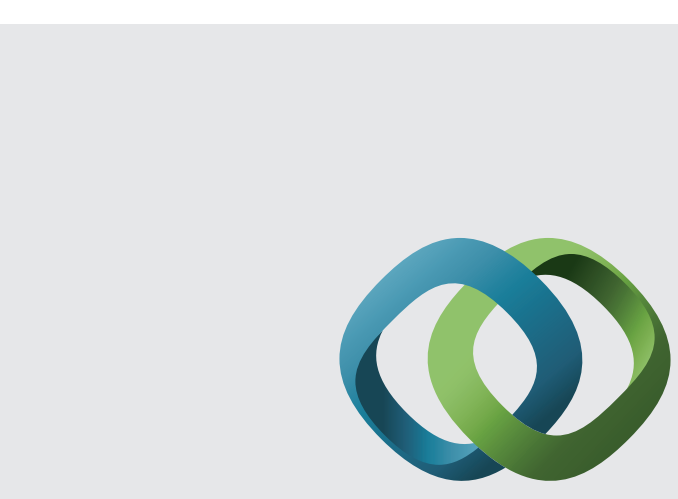

\section{Hindawi}

Submit your manuscripts at

http://www.hindawi.com
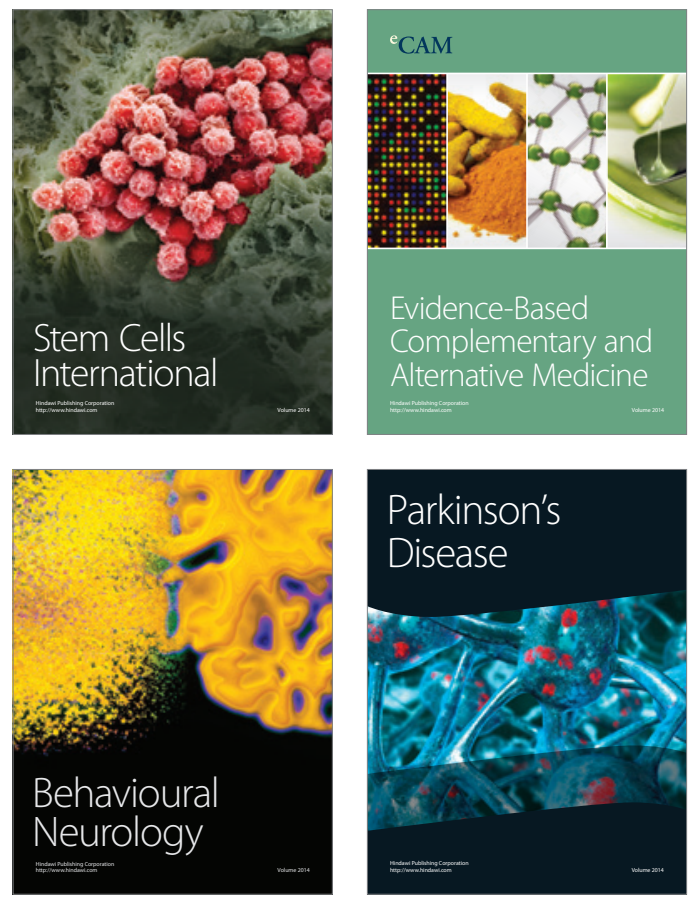
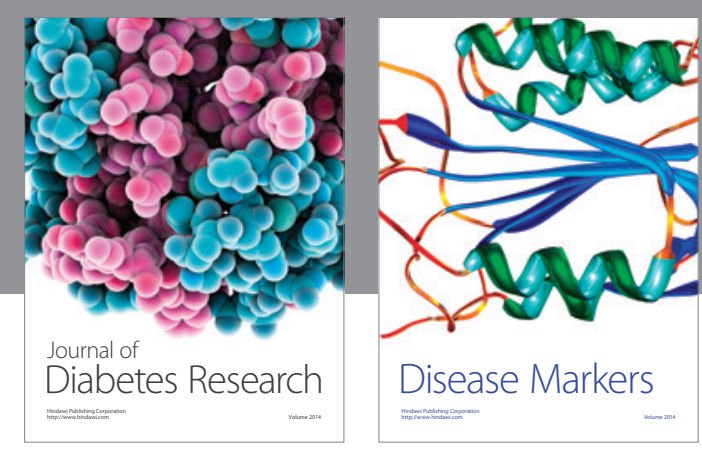

Disease Markers
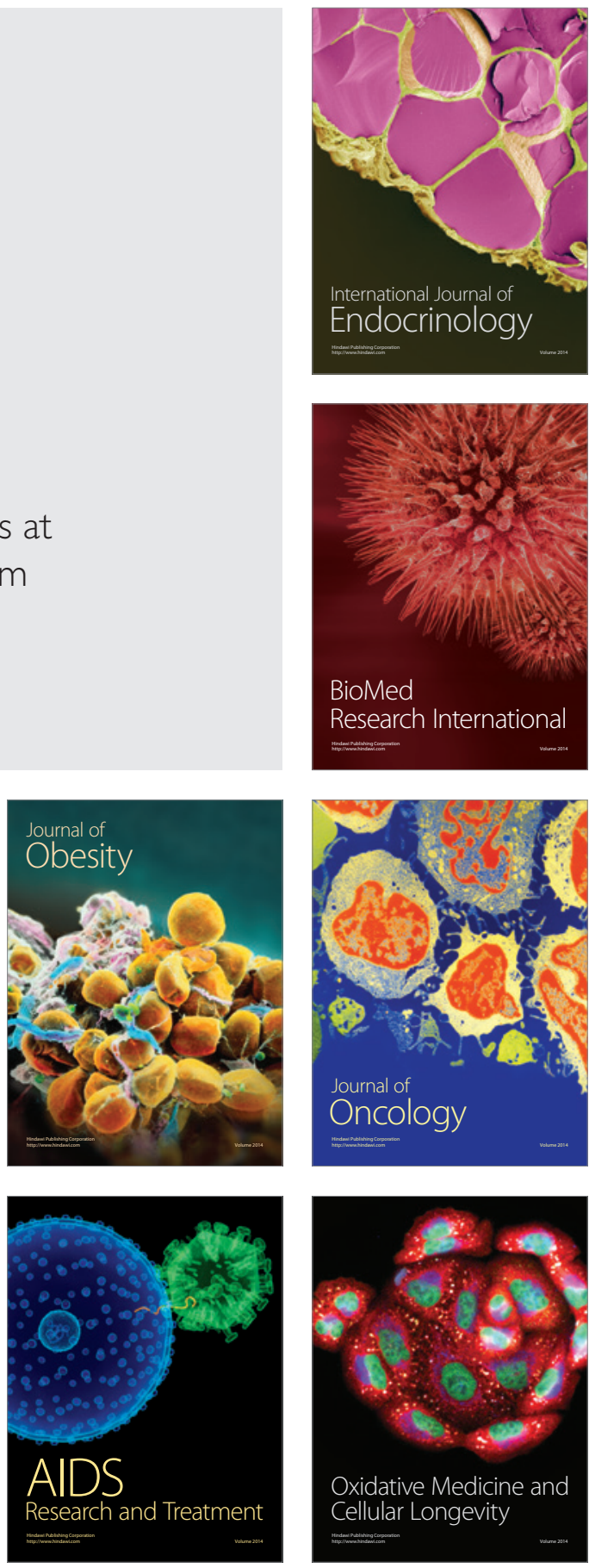